\title{
Tsafon
}

Revue d'études juives du Nord

$80 \mid 2020$

Varia

\section{Les études juives dans la diversité}

\section{Danielle Delmaire}

\section{(2) OpenEdition}

Journals

Édition électronique

URL : https://journals.openedition.org/tsafon/3091

DOI : 10.4000/tsafon.3091

ISSN : 2609-6420

\section{Éditeur}

Association Jean-Marie Delmaire

\section{Édition imprimée}

Date de publication : 1 décembre 2020

Pagination : $9-12$

ISSN : 1149-6630

\section{Référence électronique}

Danielle Delmaire, «Les études juives dans la diversité », Tsafon [En ligne], 80 | 2020, mis en ligne le 01 décembre 2020, consulté le 24 juin 2021. URL : http://journals.openedition.org/tsafon/3091 ; DOI : https://doi.org/10.4000/tsafon.3091 


\section{Dossier}

rassemblé par Christophe Batsch et Michèle Tauber présenté par Danielle Delmaire

Les études juives dans la diversité 
Tsafon 80 
Le dossier est très composite, les articles ne présentent que peu d'unité. Rassemblés par Christophe Batsch et Michèle Tauber, ils étaient initialement destinés à nourrir la rubrique «varia» d'un numéro. L'organisation particulière $\mathrm{du} \mathrm{n}^{\circ} 79$ dont le dossier était volumineux avait repoussé la parution de ces articles. Il a donc fallu les publier sans tarder et les unir malgré leur diversité dans un dossier particulier puisque sa thématique est précisément diverse. Cette contrainte a au moins le mérite de mettre en évidence la pluridisciplinarité des études juives, couvrant la Bible et les textes afférents, l'histoire depuis la plus haute Antiquité jusqu'à nos jours, la sociologie quelle que soit l'aire géographique où se trouve le groupe étudié, le sionisme et son prolongement dans l'étude de l'État d'Israël par les politologues, l'art dans toutes ses disciplines etc. L'énumération ne peut être exhaustive !

Notre dossier se limite à quelques thèmes: l'approche de textes midrashiques, la littérature et surtout la poésie, l'attrait exercé par l'idéologie nazie sur un digne professeur bibliste de l'Université allemande, le cheminement historiographique de Zeev Sternhell ce savant qui affronta les critiques de ses collègues, plus particulièrement en France, enfin une déconstruction des fantasmes concernant les ouvriers du diamant. Bref, un dossier certes diversifié mais non pas hétéroclite.

À partir d'un corpus de douze textes rabbiniques, José Costa met en évidence le discours anti-juif répandu dans les milieux païens et chrétiens de l'Antiquité tardive, des $\mathrm{V}^{\mathrm{e}}$ et $\mathrm{VI}^{\mathrm{e}}$ siècles. "Les Nations du monde narguent (les enfants d')Israël » répètent ces textes pour dénoncer une polémique hostile aux juifs. Les réponses qui sont apportées à des accusations attestent d'une réaction rabbinique structurée et bien construite. La polémique ne se cantonne pas dans les bassesses.

Trois articles pouvaient offrir une relative unité au dossier dans la mesure où ils s'intéressent à une poétesse et à deux auteurs. Toutefois, l'approche n'est pas tout à fait la même. 
Grand lecteur et admirateur de la poétesse Rachel, Bernard Grasset qui a déjà fourni à Tsafon un article sur elle dans le $n^{\circ} 78$ (automne 2019 - hiver 2020), s'émerveille maintenant, à juste titre, à propos de ses talents de traductrice. Poétesse, certes mais également polyglotte Rachel a traduit des poètes de langues diverses. Elle a surtout été très sensible à la musicalité des symbolistes d'expression française, son séjour en France l'avait familiarisée avec cette poésie. Ses traductions témoignent d'une grande maîtrise de la langue française tout autant que des rythmes de la poésie du courant symboliste. Avec minutie, B. Grasset relève, souligne, marque les efforts de Rachel pour rendre en hébreu, qui n'est pas sa langue maternelle, les particularités des poèmes retenus. Le choix d'ailleurs révèle les affinités de la poétesse avec ses pairs d'expression française.

Praticien hospitalier dans un service de psychiatrie, Olivier Taïeb lit Le conteur de Walter Benjamin avec la sensibilité de l'expert en psychiatrie voire psychanalyse. Il explore l'œuvre de Benjamin pour mettre en évidence une «crise du récit» et une «crise de la transmission ». Les traumatismes provoqués par les terribles combats de la Première Guerre mondiale en sont responsables. Alors le rôle du conteur comme celui du transmetteur prend une autre dimension. C'est sans doute tout le mérite de cet article de mettre en évidence un aspect peu visible de l'œuvre de Benjamin. Il fallait bien sûr la compréhension d'un psychiatre pour mener cette réflexion.

Le troisième article sur la littérature emmène le lecteur vers de l'œuvre de Pierre Lasry grâce à l'analyse de Simone Grossman. Le « bouquin émissaire » que l'écrivain jette à la mer s'apparente au « bouc émissaire » sacrifié dans le désert pour parfaire le monde, purifier le peuple. Récurrent dans l'œuvre de $\mathrm{P}$. Lasry, le thème est minutieusement étudié par S. Grossman qui interroge également sur la judéité. Le thème biblique est sous jacent mais l'appartenance à un peuple à part préoccupe aussi l'auteur.

Matthias Morgenstern nous fait découvrir la face grise, voire noire, de Gerhard Kittel, éminent spécialiste du Nouveau Testament, avant, pendant et après la Seconde Guerre mondiale. Son père n'était pas moins célèbre puisqu'il publia, dans les années 1930, la très fameuse Biblia Hebraica Stuttgartensia (appelée Bible de Kittel) toujours utilisée par les exégètes actuels. Apparemment très soucieux de sa carrière, Gerhard Kittel prend ses distances vis à vis de ses collègues juifs que pourtant il 
fréquentait sans trop d'état d'âme avant d'adhérer au parti nazi. Ce qui lui valut d'être arrêté au lendemain de la défaite allemande par l'armée d'occupation française. Non seulement il fit sienne l'idéologie nazie mais il s'était compromis dans la politique raciste et n'eut aucun égard envers ses anciens collègues juifs bannis et persécutés. Sa «Défense » rédigée durant ses quelques mois d'emprisonnement visait surtout à lui permettre de récupérer un poste universitaire. Ce qu'il obtint et il parvint à faire oublier son passé nazi. Jusqu'à ce que Matthias Morgenstern sorte de la pénombre des documents pour placer en plein jour la duplicité du personnage. Son poste dans la même université que G. Kittel à Tübingen l'incitait à dévoiler la réelle personnalité de son prédécesseur. L'article a aussi le mérite de mettre en lumière les rapports entre l'Université, l’Église protestante et la politique raciste du Troisième Reich.

Le 21 juin 2020, décédait, à Jérusalem, l'historien israélien et excellent francophone pour avoir vécu son adolescence en Avignon, Zeev Sternhell. Nous avons immédiatement projeté de lui rendre hommage dans nos pages car sa personnalité et ses travaux sur les origines françaises du fascisme méritaient d'être rappelés. C'est l'historien et politologue, israélien et excellent francophone lui aussi, Denis Charbit qui accepta de remplir cette tâche. Au fil de son écriture, un bref hommage s'est développé en un copieux article, ce que nous ne déplorons guère. Ce sont surtout les idées de Sternhell que Charbit analyse. Il lit et relit avec attention les nombreux ouvrages de son aîné. Il trace le chemin poursuivi par Sternhell qui démontre comment des idéologies révolutionnaires ont rongé l'esprit des Lumières pour entraîner l'Europe vers les dictatures fascistes et la catastrophe de la Seconde Guerre mondiale. Sternhell qui situait l'origine des fascismes en France, dans la seconde moitié du XIX ${ }^{\mathrm{e}}$ siècle, s'attira une opposition farouche, pour ne pas dire les foudres, d'historiens français qui lui reprochaient de ne rien comprendre à l'histoire de la France. Ses combats, que rappelle Charbit, furent courageux.

Il en mena un autre, au sein de sa nouvelle patrie, Israël, pour dénoncer la dérive vers la droite des personnages politiques israéliens qui, au fil des années, ont délaissé le socialisme fondateur de l'État, des années 1950-1960. Il participa au mouvement Shalom Akshav [La paix maintenant] avec l'écrivain Amos Oz et s'inquiétait, peu avant son décès, d'un dévoiement ultra nationaliste s'immisçant dans une partie de la société israélienne. 
L'enfant survivant de la Shoah, était né le 10 avril 1935 à Przemysl en Pologne, orphelin de père dès 1940, il connut l'enfermement dans un ghetto. Sa mère et sa sœur furent exterminées tandis qu'il était caché chez un oncle jusqu'à la fin de la guerre. Ce fut chez un autre oncle qu'il trouva refuge en Avignon avant de monter en Israël en 1951 à l'âge de 16 ans. Citoyen israélien, il combattit dans les rangs de Tsahal durant les guerres israéliennes depuis celle du Sinaï jusqu'à celle du Liban, la Guerre des Six-Jours et la Guerre de Kippour. Il était officier de réserve. Sa carrière universitaire se déroula à Jérusalem et jusqu'à ses derniers mois de vie il animait des débats. Sa dernière apparition publique pour une rencontre à l'Institut français de Jérusalem remonte au 26 novembre 2019. L'échange avec le public francophone était modéré par Denis Charbit et portait sur son dernier ouvrage : L'histoire refoulée, sorti en 2019 aux éditions du Cerf.

Enfin le dernier article de notre dossier nous éloigne de la littérature et de l'histoire politique mais il offre une image d'un groupe social: les juifs, ouvriers du diamant à Anvers. L'intention de ses auteurs, Gérard Panczer et Stéphane Cohen-Scali, est clairement avouée de démonter les préjugés, voire les fantasmes sur les "diamantaires » juifs nécessairement riches! Avec une abondance de documents, schémas et autres courbes, ils montrent que les protestants ne sont pas étrangers à l'essor de ce commerce et de cette industrie. Les juifs séfarades sont aussi impliqués. Quant aux travailleurs de la taille du diamant, ce sont pour la plupart des juifs ashkénazes dont l'exploitation est celle que connut tous les prolétariats quelle que soit leur occupation. Cette étude détricote donc toutes ces constructions bâties sur des préjugés antisémites qui présentent les diamantaires juifs d'Anvers comme de riches, sinon richissimes, personnages ! Un article très salutaire. 